\title{
Effect of dietary lipid sources on lipid oxidation of broiler meat
}

\author{
A. Hugo ${ }^{2}$, S.P. Els ${ }^{1}$, F.H. de Witt ${ }^{1 \#}$, H.J. van der Merwe ${ }^{1}$ and M.D. Fair ${ }^{1}$ \\ ${ }^{1}$ Department of Animal, Wildlife and Grassland Science \\ ${ }^{2}$ Department of Microbiology, Biochemistry and Food Biotechnology \\ P.O. Box 399, University of the Free State, Bloemfontein 9300, South Africa
}

\begin{abstract}
The objective of this study was to investigate the effects of different dietary lipid sources and inclusion levels on lipid oxidation of thigh and breast muscle of male broilers. Eight isoenergetic (15.12 MJ AME/kg $\mathrm{DM}$ ) and isonitrogenous (222.8 CP/kg DM) diets were formulated, using sunflower oil (SO), high oleic sunflower oil (HOSO), fish oil (FO) and tallow (T) at $30 \mathrm{~g} / \mathrm{kg}$ and $60 \mathrm{~g} / \mathrm{kg}$ inclusion levels. Eight hundred, day-old Ross 788 broiler males were randomly allocated to the eight treatments $(n=100)$ and further subdivided into four replicates/treatment $(n=25)$. All birds received a standard diet for 14 days whereafter the experimental diets were fed for an additional 28 days until termination of the study. Birds were slaughtered under commercial abattoir conditions at 42 days of age. Carcasses from 12 birds per treatment (n $=12$ ) were trimmed for breast and thigh cuts by removing the skin. Twelve breast and thigh samples from each treatment group were stored at $4{ }^{\circ} \mathrm{C}$ for seven days under an oxygen permeable overwrap film and another 12 breast and thigh samples were vacuum packed and stored at $-18{ }^{\circ} \mathrm{C}$ for 100 days. Meat samples were used for thiobarbituric acid reactive substances (TBARS) analysis. Birds fed FO showed significantly more oxidation in both thigh and breast meat than birds from any of the other treatments during storage. These results indicated that dietary lipid sources do influence the lipid oxidation processes of broiler meat.
\end{abstract}

Keywords: Ross 788, broiler meat, oil, fat oxidation, TBARS

"Corresponding author. E-mail: dewittfh.sci@ufs.ac.za

\section{Introduction}

Dietary fatty acids are absorbed by monogastric animals and deposited in their tissues without significant modification (Rhee et al., 1990). It has been recorded that chickens could modify their lipid profile within a week after replacement of the dietary lipid source (Lopez-Ferrer et al., 2000). There is, therefore, considerable potential for the manipulation of the fatty acid profiles of poultry tissue by dietary means, thus to increase the supply of omega-3 (n-3) polyunsaturated fatty acids (PUFA) suitable for human consumption (Coetzee \& Hoffman, 2002). Researchers illustrated that by feeding the relevant dietary unsaturated fatty acids, both polyunsaturated/saturated (PUFA/SFA) ratio (Warnants et al., 1998) and omega-6/omega-3 (n-6/n-3) ratios (Wood et al., 1999) of animal adipose tissue could be altered to fall within the dietary guidelines. Hulan et al. (1989) indicated that inclusion of marine oils in poultry diets increased the long chain polyunsaturated C20 and C22 n-3 PUFA concentration in poultry tissue.

Increasing the degree of unsaturation of muscle membranes reduces the oxidative stability of the muscle. The relative oxidation rates of fatty acids containing 1, 2, 3, 4, 5 or 6 double-bonds are $0.025,1,2,4$, 6 and 8, respectively (Horwitt, 1986). The level of PUFA in n-3 enriched poultry meat can, therefore, play an important role in the susceptibility of poultry meat to lipid oxidation and is reason for concern. Lipid oxidation can lead to discoloration, drip-loss during storage, off-odour, off-flavour development and the production of potentially toxic compounds during processing of meat products (Tang et al., 2000).

The aims of this study were therefore to investigate the effects of different dietary lipid sources and inclusion levels on lipid oxidation of thigh and breast muscles of male broilers.

\section{Materials and Methods}

The experimental layout consisted of a 4 x 2 factorial design with four dietary lipid sources and two inclusion levels. Eight hundred, day-old Ross 788 broiler males were randomly allocated to eight dietary treatments $(\mathrm{n}=100 /$ treatment). Each treatment was further subdivided into four replicates (25 
birds/replicate). Birds received a commercial starter diet for the first 14 days, whereafter the experimental diets were fed for 28 days. Eight isoenergetic (15.12 MJ AME/kg DM) and isonitrogenous (222.8 g CP/kg $\mathrm{DM}$ ) diets were formulated, using sunflower oil (SO), high oleic sunflower oil (HOSO), fish oil (FO) and tallow $(\mathrm{T})$ at a $30.0 \mathrm{~g} / \mathrm{kg}$ and $60.0 \mathrm{~g} / \mathrm{kg}$ dietary inclusion level. At 42 days of age, three birds/replicate $(\mathrm{n}=$ 12/treatment) were randomly selected, weighed, marked and slaughtered at a commercial abattoir. Carcasses were cut into portions and left breasts $(n=12)$ and thighs $(n=12)$ were over-wrapped with an oxygen permeable overwrapping film and stored at $4{ }^{\circ} \mathrm{C}$ for seven days while right breasts $(\mathrm{n}=12)$ and thighs $(\mathrm{n}=$ 12) were vacuum packed and stored at $-18{ }^{\circ} \mathrm{C}$ for 100 days. Meat samples ( 2 x $5 \mathrm{~g}$ ) from each breast and thigh meat cut were used for the analysis of the thiobarbituric acid reactive substances (TBARS) by using the aqueous acid extraction method of Raharjo et al. (1992) to determine lipid oxidation. Data were analysed by means of a $4 \times 2$ factorial design using the procedures of the SAS programme (SAS, 1999) and significant differences were identified by means of Tukey's (HSD) test.

\section{Results and Discussion}

Under storage conditions fats and the lipid content of foods may undergo oxidation. The rate of oxidation depends on the fat level, profile of fatty acids and the specific storage conditions (Zanini et al., 2006). Malonaldehyde as measured by TBARS analysis is formed primarily by the oxidation of unsaturated fatty acids, with the reaction being more intense as the level of unsaturation of the fat increases (Janero, 1990). One of the major advantages of the TBARS method is that its results are highly correlated with sensory evaluation scores (Salih et al., 1987). TBARS was found to be a good indicator of fat oxidation in pork (Buckley \& Connolly, 1980), beef (Raharjo et al., 2000) and chicken meat (Pikul et al., 1989). The only TBARS standard found in literature was for raw pork. In terms of a rancid taste for raw pork, Buckley \&Connolly (1980) found a TBARS value of 1.0 to be a good cut-off point. This cut-off point was used as a guideline in this study.

Results in Table 1 indicated that lipid source at the high inclusion level $(60 \mathrm{~g} / \mathrm{kg})$ had an effect $(\mathrm{P}<0.0001)$ on fat oxidation during refrigerated storage for seven days and frozen storage of 100 days for both thigh and breast meat cuts. Thighs and breasts from birds receiving fish oil had higher $(\mathrm{P}<0.0001)$ TBARS values compared to thighs and breasts from birds receiving tallow, high oleic sunflower oil or sunflower oil. This confirms to some extent the findings of Horwit (1986) that higher levels of unsaturated fatty acids would lead to a faster rate of oxidation. One would also expect a difference between TBARS values of thighs and breasts from poultry receiving the more saturated tallow and high oleic sunflower oil compared to the more unsaturated sunflower oil. Such a difference was, however, not observed.

An important observation is the significant $(\mathrm{P}<0.05)$ effect of inclusion level of oils on TBARS values of thighs after seven days storage and thighs and breasts after 100 days storage (Table 1). This was only visible for the fish oil treatments. Thighs and breasts from poultry receiving the $60 \mathrm{~g} / \mathrm{kg}$ fish oil diet and wrapped in an oxygen permeable film had TBARS values exceeding the value of one proposed by Buckley \& Connolly (1980) as the cut-off point in terms of rancid tastes after seven days of refrigerated storage. Under vacuum packaging and storage for 100 days there was also a significant increase in the TBARS level, but not above one.

Another interesting observation is the effect of packaging method on oxidative stability of chicken meat with varying fatty acid profiles. Although not statistically compared, TBARS values of thighs and breasts that were vacuum sealed and stored at $-18^{\circ} \mathrm{C}$ for 100 days seemed to be lower than that of thighs and breasts that were stored under oxygen permeable overwrap film at $4{ }^{\circ} \mathrm{C}$ for seven days for all treatments. In the case of the fish oil treatments this packaging effect was especially very noticeable. These results should be interpreted with caution as no statistical analyses have been done. It seems, however, that food technologists that develop packaging systems for chicken meat must take cognisance of these findings. These results clearly indicate that oxidative processes in chicken meat rich in polyunsaturated fatty acids may be inhibited by low temperature storage in the absence of oxygen.

There was a significant $(\mathrm{P}<0.0002)$ source $\mathrm{x}$ inclusion level interaction on the TBARS values of both meat cuts. This interaction can probably be ascribed to a dose response decrease in oxidative stability with increased levels of highly unsaturated n-3 PUFA. Exposure of the birds to higher fish oil levels led to a higher n-3 PUFA content in the tissue compared to birds receiving lower fish oil levels and this is reflected in the oxidative stability of meat (Horwitt, 1986). 
Table 1 The effect of dietary lipid sources at different inclusion levels (30 and $60 \mathrm{~g} / \mathrm{kg}$ ) on the thiobarbituric acid reactive substances (TBARS - mg malonaldehyde/kg meat) of chicken meat cuts stored under different conditions (Means)

\begin{tabular}{ccccccccc}
\hline & \multicolumn{9}{c}{ Lipid source } & \multicolumn{3}{c}{ Significance (P) } \\
\hline Parameter & $(\mathrm{g} / \mathrm{kg})$ & $\mathrm{SO}^{1}$ & $\mathrm{HOSO}^{2}$ & $\mathrm{FO}^{3}$ & $\mathrm{~T}^{4}$ & Source & Inclusion & Interaction \\
\hline Thigh & 30 & $0.30^{\mathrm{a} 1}$ & $0.26^{\mathrm{a} 1}$ & $0.84^{\mathrm{b} 1}$ & $0.32^{\mathrm{a} 1}$ & $<0.0001$ & 0.0002 & $<0.0001$ \\
$\begin{array}{c}\text { (7 d }) \\
\text { Breast }\end{array}$ & 60 & $0.30^{\mathrm{a} 1}$ & $0.22^{\mathrm{a} 1}$ & $2.30^{\mathrm{b} 2}$ & $0.28^{\mathrm{a} 1}$ & & & \\
$(7 \mathrm{~d})$ & 30 & $0.34^{\mathrm{a} 1}$ & $0.26^{\mathrm{a} 1}$ & $0.35^{\mathrm{a} 1}$ & $0.28^{\mathrm{a} 1}$ & $<0.0001$ & 0.1153 & $<0.0001$ \\
& 60 & $0.11^{\mathrm{a} 1}$ & $0.18^{\mathrm{a} 1}$ & $1.00^{\mathrm{b} 1}$ & $0.25^{\mathrm{a} 1}$ & & & \\
Thigh & 30 & $0.13^{\mathrm{a} 1}$ & $0.11^{\mathrm{a} 1}$ & $0.23^{\mathrm{a} 1}$ & $0.11^{\mathrm{a} 1}$ & $<0.0001$ & 0.0279 & $<0.0002$ \\
$(100 \mathrm{~d})$ & 60 & $0.09^{\mathrm{a} 1}$ & $0.07^{\mathrm{a} 1}$ & $0.59^{\mathrm{b} 2}$ & $0.14^{\mathrm{a} 1}$ & & & \\
Breast & 30 & $0.08^{\mathrm{a} 1}$ & $0.07^{\mathrm{a} 1}$ & $0.15^{\mathrm{a} 1}$ & $0.10^{\mathrm{a} 1}$ & $<0.0001$ & 0.0365 & $<0.0001$ \\
$(100 \mathrm{~d})$ & 60 & $0.06^{\mathrm{a} 1}$ & $0.06^{\mathrm{a} 1}$ & $0.34^{\mathrm{b} 2}$ & $0.08^{\mathrm{a} 1}$ & & &
\end{tabular}

${ }^{\mathrm{a}, \mathrm{b}}$ Row means with different superscripts differ significantly $(\mathrm{P}<0.05)$ within parameter means;

${ }^{1,2}$ Column means with different superscripts differ significantly $(\mathrm{P}<0.05)$ within parameter means.

${ }^{1}$ Sunflower oil; ${ }^{2}$ High oleic sunflower oil; ${ }^{3}$ Fish oil; ${ }^{4}$ Tallow.

\section{Conclusions}

Although it is possible to manipulate the levels of saturated-, mono-unsaturated-, omega-6- or omega3 fatty acids in poultry meat by dietary intervention to fall within dietary guidelines, results from this study demonstrated that poultry meat samples from different dietary oil treatments vary in oxidative stability. The results indicated that there were no significant differences between the oils high in n- 6 fatty acids but that the n-3 fatty acid containing FO leads to oxidative unstable fat in the chicken meat.Thigh and breast cuts from animals receiving stable more saturated (tallow), mono-unsaturated oils (high oleic sunflower oil) and polyunsaturated sunflower oil (n-6) were more stable than cuts from animals receiving polyunsaturated fish oil rich in (n-3) fatty acids as part of their diet. These results clearly indicate that dietary lipid sources do influence the lipid oxidation processes of broiler meat and consequently the storage period of chicken meat. There was a significant inclusion level effect only in the case of fish oil feeding.

Thigh and breast cuts from the higher $(60 \mathrm{~g} / \mathrm{kg})$ dietary inclusion level of fish oil exceeded international norms for acceptable TBARS values within seven days of refrigerated storage under oxygen permeable overwrap film. Animal nutritionists that formulate poultry diets with the aim of enhancing the nutritional and health properties of meat by using increased levels of polyunsaturated n-3 fatty acid from fish oils in the diets, must keep this result in mind. By increasing levels of, preferably, natural antioxidants such as vitamin $\mathrm{E}$ in the diets, the oxidative stability of such meat may be improved.

In the absence of oxygen and during storage at $-18{ }^{\circ} \mathrm{C}$ for 100 days TBARS values of chicken receiving the fish oil diets were still within international norms. It is suggested that packaging of poultry meat also be evaluated to see whether oxygen impermeable films could improve stability. The use of vacuum packaging of omega-3 fatty acid enriched chicken during refrigerated storage may be a means to keep TBARS values within an acceptable range.

\section{References}

Buckley, J. \& Connolly, J.F., 1980. Influence of alpha-tocopherol (vitamin E) on storage stability of raw pork and bacon. J. Food Prot. 43, 265-267.

Coetzee, G.J.M. \& Hoffman, L.C., 2002. Effects of various dietary n-3/n-6 fatty acid ratios on the performance and body composition of broilers. S. Afr. J. Anim. Sci., 29, 175-184. 
Horwitt, M.K., 1986. Interpretations of requirements for thiamin, riboflavin, niacin-tryptophan, and vitamin E plus comments on balance studies and vitamin B-6. Am. J. Clin. Nutr. 44, 973-985.

Hulan, H.W., Ackman, R.G., Ratnayaka, W.M.N. \& Proudfoot, F.G., 1989. Omega-3 fatty acid levels and general performance of commercial broilers fed practical levels of redfishmeal. Poult. Sci. 68, 153-162.

Janero, D.R., 1990. Malonaldehyde and thiobarbituric acid reactivity as diagnostic indices of lipid peroxidation and peroxidative tissue injury. Free Rad. Biol. Med. 9, 515-540.

Lopez-Ferrer, S., Baucells, M.D., Barroeta, A.C. \& Grashorn, M.A., 2000. n-3 Enrichment of chicken meat. 1. Use of very long-chain fatty acids in chicken diets and their influence on meat quality: Fish oil. Poult. Sci. 80, 741-752.

Pikul, J., Leszczynski, D.E. \& Kummerow, F.A., 1989. Evaluation of three modified TBA methods for measuring lipid oxidation in chicken meat. J. Agric. Food Chem. 37, 1309-1313.

Raharjo, S., Sofos, J.N.S. \& Schmidt, G.R., 1992. Improved speed specificity, and limit of determination of an aqueous acid extraction thiobarbituric acid- $\mathrm{C}_{18}$ method for measuring lipid peroxidation in beef. J. Agric. Food Chem. 40, 2182-2185.

Rhee, K.S., Davidson, T.L., Cross, H.R. \& Ziprin, Y.A., 1990. Characteristics of pork products from swine fed a high monounsaturated fat diet: Part 1 - Whole muscle products. Meat Sci. 27, 329-341.

Salih, A.M., Smith, D.M., Price, J.F. \& Dawson, L.E., 1987. Modified extraction 2-thiobarbituric acid method for measuring lipid oxidation in poultry. Poult. Sci. 66, 1483-1488.

SAS, 1999. SAS ${ }^{\circledR}$ Users guide. Version 6.12. SAS Institute Inc. Carey, N.C., USA.

Tang, S.Z., Kerry, J.P., Sheehan, D., Buckley, D.J. \& Morrissey, P.A., 2000. Dietary tea catechins and iron induced lipid oxidation in chicken meat, liver and heart. Meat Sci. 56, 285-290.

Warnants, N., Van Oeckel, M.J. \& Boucqué, C.H.V., 1998. Effect of incorporation of dietary polyunsaturated fatty acids in pork backfat on the quality of salami. Meat Sci. 49, 435-445.

Wood, J.D., Sheard, P.R., Enser, M., Nute, G.R., Richardson, R.I. \& Gill, B.P. 1999. Increasing the n-3 polyunsaturated fatty acid content of pig meat and effects on meat quality. Proc. $45^{\text {th }}$ Int. Congr. Meat Sci. Technol, Yokohama, Japan. pp. 672-673.

Zanini, S.F., Colnago, G.L., Bastos, M.R., Pessotti, B.M.S., Casagrande, F.P. \& Gill, V.R., 2006. Oxidative stability and total lipids on thigh and breast meat of broilers fed diets with two fat sources and supplemented with conjugated linoleic acid. LWT-Food Sci. Technol. 39, 717-723. 